\title{
Truthful Engagement: Making the Witness Blanket, an Ongoing Process of Reconciliation
}

\author{
Carey Newman - Hayalthkin'geme with Catherine Etmanski
}

\begin{abstract}
This report from the field summarizes a conversation between Carey Newman and guest editor, Catherine Etmanski, which took place on January 12, 2018. The conversation focused on Carey's work engaging people across Canada in a project titled The Witness Blanket. The Witness Blanket is a national monument of the Indian Residential School Era made of items collected from residential schools, from churches, government buildings, and traditional structures from across Canada. In this report, Carey provides insight into the process of collecting artefacts from communities across Canada. Although not all pieces he received were aesthetically pleasing-and neither were the stories associated with them - through this process, he learned the importance of including all voices and stories. With time and reflection, he learned the power of collective truth. While making the Witness Blanket, some items challenged his creativity and tested his commitment to include something from every contributor, but he felt a responsibility to find a place for them all. He also brings focus to traditional perspectives or ways of being that helped guide him through the process of building and leading a team through the expansive community engagement process and the eventual creation of a monument, national tour, and documentary film.
\end{abstract}

KeyWords The Witness Blanket, Truth and Reconciliation, collective truth, national engagement

This report from the field summarizes a conversation between Carey Newman and guest editor, Catherine Etmanski, which took place on January 12, 2018. The conversation focused on Carey's work engaging people across Canada in a project called The Witness Blanket. The Witness Blanket is a national monument of the Indian Residential School Era made of items collected from residential schools, from churches, government buildings, and traditional structures across Canada. Through these tangible objects, it weaves together a comprehensive narrative of both survivor experience and history of residential schools in Canada. Each of the items included in the Witness Blanket has a multitude of stories attached to it. Carey not only designed the 40' multimedia installation, he was also the project manager. He attained the commission through a national call for proposals by the Truth and Reconciliation (TRC) Commission. Here is his story. 


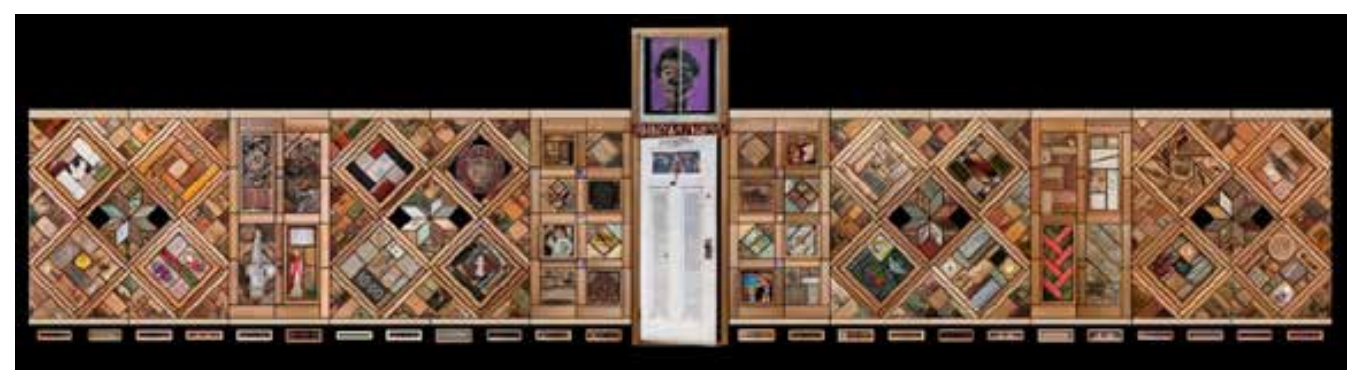

Figure 1. Composite image of the complete Witness Blanket. Photo Credit: Media One Inc.

\section{The Naming Process}

It was a blanket before it was a Witness Blanket. My original concept was to string objects together like a big beaded bracelet and make a blanket of solid objects. I wanted it to be a blanket for multiple reasons, especially because blankets have particular significance in both of my Indigenous cultures: Kwakwaka'wakw and Salish.

We have different ways that we use blankets across cultures and traditions. In Kwakwaka'wakw culture, blankets represent who we are. We stitch our symbols onto themour totems and family crests. We wear them in ceremony; they are part of our identity and, like a name tag, they identify our lineage. In my Salish tradition, we use blankets to honour, uplift, and protect people. If somebody has achieved something wonderful for the community, we acknowledge that through putting a blanket around them as a gesture of gratitude. If someone has gone through trauma, we do the same thing as a gesture of protection.

Expanding that out to the rest of the world, I think about how we wrap our babies in blankets when they are born, or how we often wrap our loved ones in blankets when they pass on. The blanket carries symbolic importance in almost every culture. So, I chose a blanket because it is a good universal symbol.

As for the name of the project: it came from my wife Elaine listening to CBC Radio. They were covering the Truth Reconciliation Commission gathering in my home territory on the northern part of Vancouver Island. The reporter was interviewing people and when he asked a priest why he was there, he said simply, "I'm here to bear witness." After hearing that, my wife called me immediately and she said, "Bear witness; bear witness_-it's about bearing witness." I looked up the definition and found something along the line of "to show by your existence that something is true," and realised it was perfect, because it is about bearing witness. My role as an artist is to bear witness. The pieces themselves are witnesses. The people giving us the pieces are witnesses, and at some level, we are all, or we should all be, witnesses.

There is also a cultural connection because in both Kwakwaka'wakw and Salish oral traditions, we have witnesses. That is how we preserve history or important moments. In Kwakwaka'wakw ways we hold potlatches to tell our stories, then we give gifts to our guests and ask them to remember what they saw. In the Salish tradition, we ask people to stand and speak about what they have witnessed. Then we acknowledge them by giving tokens or paying them to carry our history. 
Following that tradition, we created our own little Witness Blanket coins to acknowledge those who made contributions or helped us along the way. Everywhere we went we gave out these coins that said, "Thank you," in many different languages. That is how the traditions of "Witness" and "Blanket" came together.

\section{Project Conception}

The call from the TRC was for commemoration initiatives. They outlined that you could do an individual project, a regional project, a provincial project—or you could do a national project.

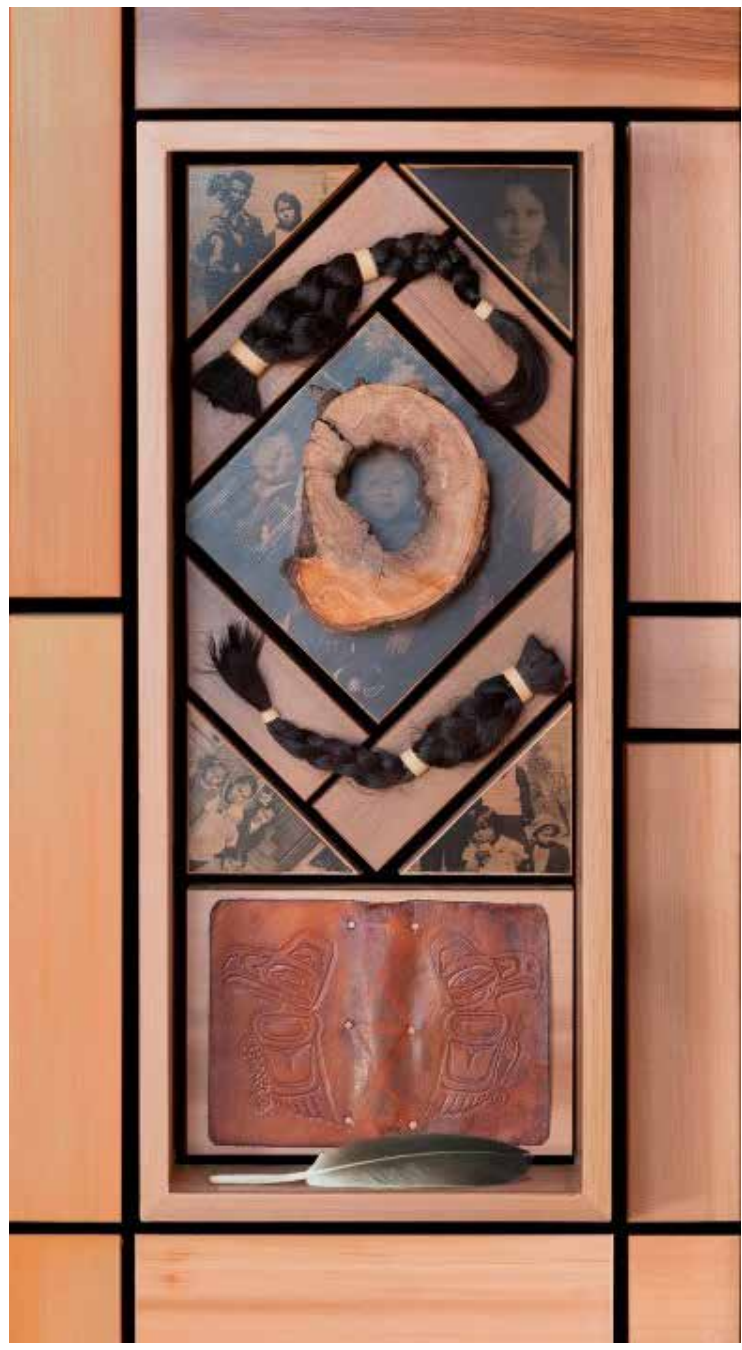

Figure 2. Detail of panel from Witness Blanket: Braids and photos of Newman family. Photo Credit: Media One Inc.
I wanted to do a national project because I wanted to tell the whole story of residential schools in Canada.

I began by thinking about everything I do as an artist-carving totems and sculptures - and one by one I dismissed each medium I've worked with in the past. Every idea I had felt too small. The perspective was always too regional, or too individual to tell a national story. I quickly realised that to tell a comprehensive story about the experience of residential schools, I needed to step outside anything I'd done before.

That was when I came up with the idea of gathering objects. I was sitting in my living room and I had my feet on this little folding stool made from bits of wood that strung together. I thought to myself, I'll do this, but bigger. I'll create a blanket made of solid objects. That way I can gather pieces from all the schools, and collectively, like a huge patchwork quilt, they will tell the whole story. That was my eureka moment where I really felt like I was finally on the right track.

The original idea was to include only pieces from residential schools. As I thought more about it, I realised I should include churches and government buildings because they're part of the same story. Government buildings are where the decisions and policies that led to the 
schools were made. Churches operated the schools.

The final thing I realised was that the story didn't end when the last residential school was closed in 1996. The impacts persist in our communities. The people and cultures that were targeted have survived. So, to give voice to that resilience and reflect that the work of healing continues, I decided to include traditional structures, healing centres, and other contemporary Indigenous buildings. That is how I came up with the idea. It was based on a desire to find a way to tell the whole story.

\section{Defining Reconciliation and Collective Truth}

As I was planning the engagement process, I made a document examining the words "truth" and "reconciliation." I knew that some people didn't agree with the phrase "Truth and Reconciliation," and were unlikely to participate in TRC events or projects. In an effort to be as inclusive as possible, I wrote definitions that, in a way, addressed those concerns.

This document outlined various meanings reconciliation might have to different people participating in the project; it also acknowledged that some people would reject the word completely. One of the dictionary definitions of reconciliation is, "to be brought back into the church." Considering the problematic relationship many survivors have with organised religion, I explicitly said, "That's not our definition." Another definition was "to re-establish good relations." Many people feel that there were never good relations in the first place, so we weren't re-establishing good relations either. Reconciliation can be personal or public; individual or institutional. For the most part, we were talking about reconciliation on a personal level. For the Witness Blanket, we accepted reconciliation to be whatever stage somebody was at in their process of healing. By this, we were saying that reconciliation meant different things for different people, and it is whatever anybody wants it to be for themselves.

Early on, we had people saying that they didn't believe in reconciliation and asking whether they could even take part in this project. My response was, "What do you believe in?" And if they were angry, or sad, or ready to forgive but not forget, then I'd say, "Then that is where you are. That's your truth. So absolutely you can participate." At that stage, I wasn't presenting a particular position. I was trying to create a space where stories can exist, and truth can emerge. Removing my own opinion was an important part of gathering the most accurate narrative possible.

In defining truth, this document was the beginning of my idea around collective truth. To me this meant taking all the stories and objects as they come in, and not holding any individual story up against a test of veracity. Rather, accepting them all at face value and knowing that within that collective, is the truth. Truth exists differently for different people. Two people can tell the story of the same interaction and hold vastly different interpretations of what happened. Even though, if you were to observe it from the outside, there is baseline fact, truth is kind of fluid; the unique truth felt by two different people, about the same event, is equally true for both. They are part of the collective truth.

I didn't really come up with the phrase "collective truth" until recently, but I think it was seeded during the thought process of defining truth. I went into the project thinking that

Engaged Scholar Journal: Community-Engaged Research, Teaching and Learning 
truth is absolute. Truth is one thing. There is one truth. But as I started to think about what the definition was going to look like, I began to realise that there were going to be various truths for various people. This meant that the more fragments I gathered, the more accurate the collective truth would become.

In this project, I also set a hierarchy of truth that started with survivors and then moved forward through generations. If there was a conflict of interpretations, then we had a starting point to find a resolution. Centering the survivors' truth in a structural way early on, helped us to centre survivors in our approach. I was mindful of survivors because their courage, grace, and generosity made the project possible. Beyond their willingness to share their stories and keepsakes, the funding for commemoration projects came directly from the Indian Residential Schools Settlement Agreement (IRSSA). That means that every single survivor paid out of their own pocket to create a twenty million dollar fund to enable commemoration projects.

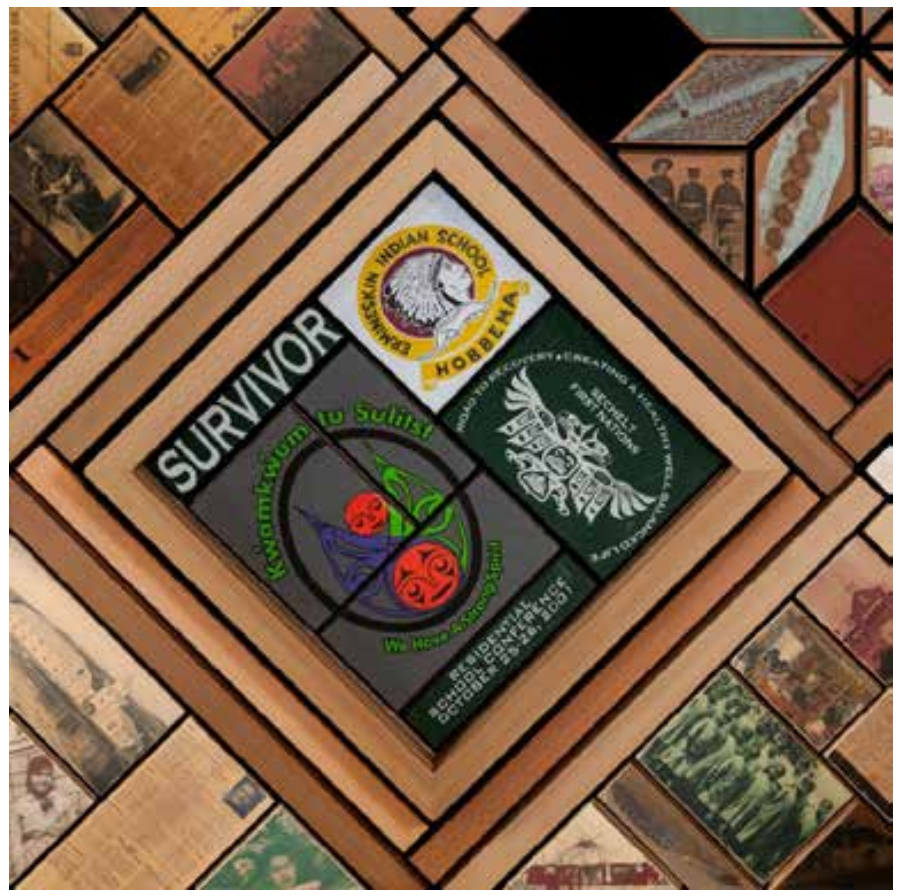

Figure 3. Detail of the Witness Blanket with survivor T-shirts. Photo Credit: Media One Inc.

\section{The Process of Engagement}

Probably the biggest thing I had going for me in the beginning was recognising that I didn't know very much, and that part of the process of engagement was to listen and learn. I wanted the result to reflect the process and for the process to model reconciliation. Knowing this, I couldn't go in with a concrete idea I was unwilling to change. I had to start with a concept and keep it fluid, letting it grow and morph based on what was learned through engagement.

When it came to explaining the project, I designed a logo and built an information package 
that detailed the concept. This included paper pamphlets, a website, smaller postcards, buttons, witness coins, and thank you blankets. To connect with survivors, we started attending TRC events. We also went to various Indigenous health forums and conferences and we talked to as many people as possible. Through that, we were introduced to the TRC's health support workers' network, which became a really important relationship for us. Health support workers had experience within the communities we visited, and a good sense of which survivors were ready to participate in this kind of project. That is how we got most items from residential schools. For accessing traditional and contemporary Indigenous structures, we used largely the same process. By connecting through communities, we received objects from sweat lodges, Indigenous Friendship Centres, and other commemoration projects.

By connecting with the health support network in each community, we were also building the supports they offered into our engagement process. This was particularly important because we were dealing with sensitive issues, and just asking someone to remember can

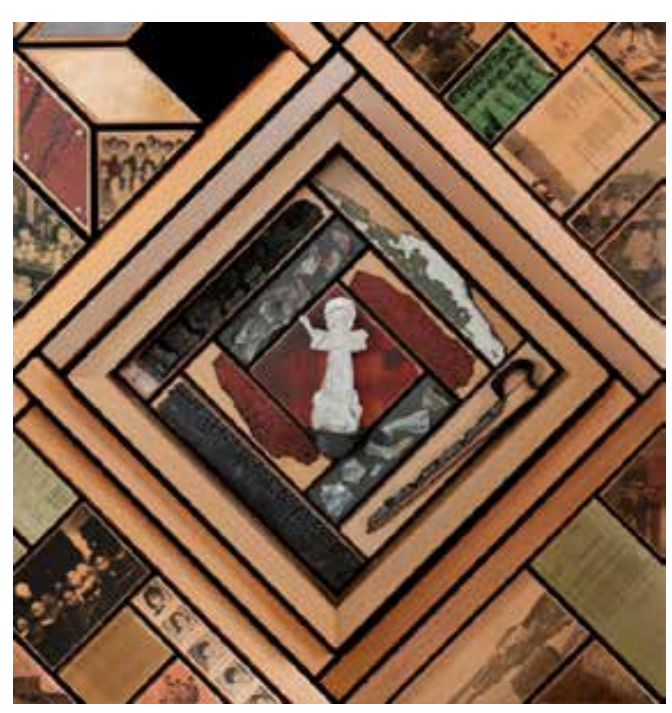

Figure 4. Detail-Figurine collected from Crowfoot Indian Residential School in Cluny,

AB. Photo Credit: Media One Inc. trigger harmful or traumatic memories. No one on our team was a professional in confronting or dealing with trauma so part of our strategy was to engage those support services locally.

For engaging churches, representatives were often at the TRC events, so we were able to talk to them there. Sometimes, individual churches were eager to participate saying, "We're committed to reconciliation. We'll send you (for example) a piece of a pew." Other times, particularly at the national level, it was much more onerous, and was similar to engaging government.

When it came to collecting artifacts from government buildings, the process was about letter writing and calling people we knew. For some of them, we sent a letter with our request, and they sent us back a piece with an explanation. Others had a lot of questions and concerns. They wanted to make sure they weren't admitting any liability or participating in something that would put them at risk, so we had to be measured about our requests. We made sure to say that this was not going to be used to shame or to call out people or organizations. This was representational. Having a piece of parliament or legislative buildings, for instance, was important to this project because decisions were made in those halls that affected the history of this country, particularly residential school history. Once they understood what the project was, most were willing to participate in some way. With government engagement, either you need to know somebody, or you just have to keep banging on the door until they finally answer, so persistence is the key. 


\section{Preparing for the Emotional Labour of Engagement}

Throughout this project, we took on a lot of people's emotions and stories. Going in I knew this would be the case, and made sure that, as a team, we were properly prepared. We did this through acknowledgement and by making sure we were open with one another regarding our feelings and emotional states. We also employed a few different traditional practices along the way. One of them was smudging with traditional medicines like sage, sweetgrass, or tobacco. Another was "Shokwams" or spiritual baths in freezing water at dawn. The most common was having cedar boughs present to "brush" ourselves off, so that we didn't transfer the emotional weight of our work onto others, or carry it with us into our personal lives.

I was prepared for the weight of the stories. I was prepared to be gentle with myself and those who participated. What I didn't anticipate and prepare for was the power I was going to feel from individual items. I got an important lesson early on that came from Rosy, a member of the team. She was in Carcross where she collected a child's shoe from the site of a burned-down residential school.

The day after she returned, I got a knock at my door at 8:30 in the morning, which was unusual. It was Rosy. She said, "I'm sorry that I have to do this, but..." and she had this little box with the shoe inside and told me this story. The evening of the day she collected the shoe, she woke up in the middle of the night feeling terribly afraid, running from something in her sleep. It really shook her. That day, she travelled home and, forgetting about her experience, dropped her bags and spent some down-time with her husband. Then he woke up in the middle of the night having the exact same nightmare, running from something in his sleep. She thought, "It has to be the shoe," and brought it straight over.

When I received the shoe and the story, I wasn't sure what to do, but recognised that I needed to address it in some way. That evening I took out the box, removed the shoe, and just held it. I still get emotional when I talk about it, because I don't often feel that kind of emotion from an object. I held it and tried to identify the feeling it carried. The closest I could understand was that it wasn't anger; it was fear. Not knowing what else to do, I started to talk about the project. There I was,

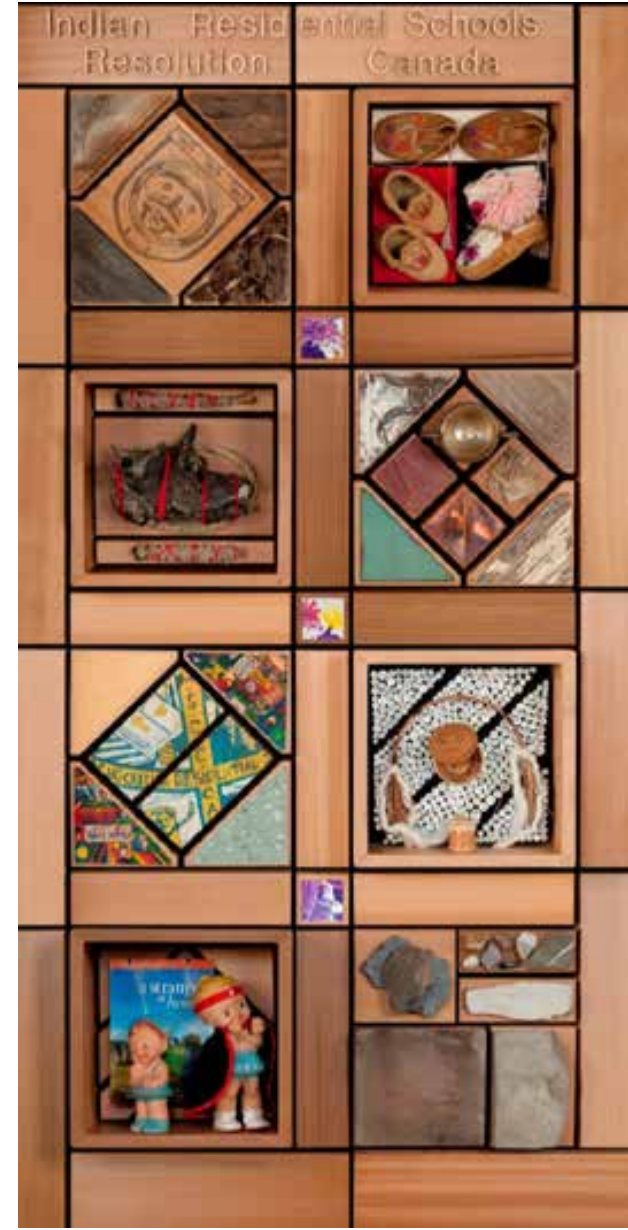

Figure 5. Panel from Witness Blanket with child's shoe.

Photo Credit: Media One Inc. 
trying to appease my own fears, while also trying to calm the unsettled spirit or power that came with this little shoe. So, I talked about what I was doing, about my intentions, about what the blanket was. In a way I was asking for consent or approval, but saying those things out loud also helped me solidify and clarify the project in my own mind.

I repeated this process each night for the first week. Each time the shoe felt a little bit different. I went from sensing fear and frenetic energy, slowly to sadness, and then acceptance, but still sadness. I didn't ever have the experience of waking up in the night, but having the shoe arrive early in the process taught me that I needed to respect the objects, stories, and people equally.

This shifted my thought process, and likely the final work itself. Rather than just being disparate "things" I was sticking onto this blanket, I recognised them as sacred. From that point on, it became part of my practice to take a moment to connect with each piece as it came in. I had to engage them with care. I had to curate with some sense of understanding and fairness, so that I wasn't picking the things that I liked because they were pretty or because they created a nice texture; there had to be equity in the way that I was organising the items.

I'm not an overly spiritual person, but sometimes moments come along in your life and you can't deny their impact. Having that shoe come when it did, with the realisations it brought, was a big part of helping me to understand the magnitude of what it was going to mean to bring all of those objects together in the blanket.

\section{Moving Forward with the Responsibility to Support Other Artists}

I have come to realise that taking on this project includes a responsibility to continue this work. With the tour winding down, I'm in the process of deciding where the Witness Blanket will live. This is a challenging transaction because, although I don't feel any ownership over the blanket, I feel responsible for its stewardship. Instead of a traditional sale, I want to find a way to reinvest the trust and capital that enabled me to complete this project, to provide similar opportunities for other artists and other projects. I don't yet know what form that will take, but I know that artists rarely have a large budget and complete creative autonomy to move their artistic vision forward. For me, the process was transformative, so I am interested to see what that would turn into for others.

Through the power of everyday objects and the collective truths they represent, the Witness Blanket reaches into the hearts of many. The result is truly a reflection of the process that created it. Now, in bringing one part to a conclusion, I find myself advocating to provide the same opportunity for others. This is because I started down the pathway of truthful engagement; it comes from what I learned along the way and it will continue as long as I listen enough to learn the things I still don't know.

\section{Postscript}

At the time of publication, Carey has entered into a collaborative stewardship agreement with the Canadian Museum for Human Rights. This unique contract between an artist and a Crown Corporation recognizes the rights of the Witness Blanket itself and the stories it holds, while

Engaged Scholar Journal: Community-Engaged Research, Teaching and Learning 
responsibility for the care and best interests of the Witness Blanket rest with both Carey and the museum. In addition to a signed contract, this agreement will also be enacted through a Kwakwaka'wakw ceremony that will include the calling of witnesses so that it will exist in both oral and written forms. As a legacy, enabled partially by the terms of this agreement, Carey is in the process of establishing a Centre of Excellence for the Study of Art and Reconciliation. It his intention that this Centre will be a space where artists and scholars can examine the many ways that art, reconciliation, and decolonization intersect, and where students of all backgrounds can come together to explore, through the arts, our responsibilities to this earth and to one another. In this way, the spirit of the Witness Blanket will live on through the work of others.

\section{Acknowledgements}

The Witness Blanket described in this article was a Commemoration Initiative selected by the Truth and Reconciliation (TRC) Commission, funded through the Indian Residential Schools Settlement (IRSSA) Agreement and administered by Aboriginal Affairs and Northern Development Canada. Carey gratefully acknowledges all survivors and intergenerational survivors of Residential Schools and honours those who are no longer with us or did not survive. He acknowledges his sisters and his mother for their help, his wife Elaine for her infinite support and steady guidance, and his father Victor and daughter Adelyn for their inspirations for this project.

\section{About the Authors}

Catherine Etmanski (corresponding author) is a professor and director of the School of Leadership Studies at Royal Roads University. Through her mother, she is Irish-American, New York Dutch, and British. Through her father, she is Kashubian from Poland, and Scottish from Clan MacDonald of Clanranald. Email: catherine.etmanski@royalroads.ca

Carey Newman or Hayalthkin'geme is a multi-disciplinary artist and master carver. Through his father he is Kwagiulth from the Kukwekum, Giiksam, and WaWalaby'ie clans of Fort Rupert, and Sto:Lo from Cheam along the upper Fraser Valley. Through his mother he is English, Irish, and Scottish. Carey is the 6th Audain Professor of Contemporary Art Practice of the Pacific Northwest at the University of Victoria in the Department of Visual Arts. Email: carey@witnessblanket.ca 